\title{
Encapsulation of Tetracarbonyl(trimethylstannyl)cobalt in NaY Zeolite: Reactivity and Alloy Cluster Formation
}

\author{
Christian Huber, Karin Moller, and Thomas Bein* \\ Department of Chemistry, Purdue University, West Lafayette, Indiana 47907
}

Received: July 1, $1994^{\otimes}$

\begin{abstract}
A bimetallic precursor route toward the encapsulation of subnanometer tin-transition metal alloy clusters in zeolites is presented. The intrazeolite chemistry and thermal stability of $\mathrm{Me}_{3} \mathrm{SnCo}(\mathrm{CO})_{4}$ in $\mathrm{NaY}$ zeolite were studied with X-ray absorption spectroscopy (Sn, Co edge EXAFS) and in-situ FTIR/TPD-MS techniques. In the $\mathrm{NaY}$ host, the intact precursor is physically adsorbed from hexane solution into the dehydrated zeolite cages at room temperature without further chemical reaction. Symmetry changes of the $\mathrm{Co}(\mathrm{CO})_{4}$ moiety indicate interaction of the $\mathrm{CO}$ ligands with the $\mathrm{Na}^{+}$ions of the zeolite framework. The intrazeolite complex in $\mathrm{NaY}$ is accessible to external reactants and undergoes carbonyl substitution with $\mathrm{PMe}_{3}$ at the cobalt center. The encaged organometallic complex is stable up to about $90^{\circ} \mathrm{C}$ and then decomposes by loss of CO ligands and rearrangement of the $\mathrm{Sn}-\mathrm{Co}$ structure, resulting in metal clusters with bridging carbonyl ligands. At about $300^{\circ} \mathrm{C}$, all $\mathrm{CO}$ is removed, and very small tin-cobalt alloy clusters are formed as detected with EXAFS spectroscopy. This process is also observed in porosity measurements showing successive recovery of free volume on $\mathrm{CO}$ removal.
\end{abstract}

\section{Introduction}

It is of great interest to tailor the reactivity of metal catalysts to fit a desired product distribution in catalytic transformations. In this context, bimetallic ("alloy") catalysts have attracted great attention for many years. This interest is based upon the potential enhancement of the catalytic activity, selectivity, and stability as well as possible insights into reaction mechanisms. ${ }^{1-3}$ One of the most important applications of heterogeneous bimetallic catalysts is the catalytic reforming of naphtha fractions, particularly the conversion of alkanes and cycloalkanes to aromatics based upon modified group VIII metal catalysts. The introduction of a second metal such as Re or Sn was observed to change the selectivities of competing hydrogenolysis/dehydrocyclization and other reactions and to enhance the lifetime of the catalyst. These effects have been discussed in terms of ensemble requirements (dilution of the group VIII metal surface species such that structure-sensitive hydrogenolysis reactions are suppressed or enhanced by the presence of mixed ensembles ${ }^{4}$ ), modification of deactivating carbonaceous layers, and improved metal dispersion through "anchoring" via the second metal. ${ }^{5}$

Sinfelt and co-workers ${ }^{6}$ and others ${ }^{7,8-11}$ have performed indepth studies of bimetallic clusters on high surface area metal oxide supports (prepared by classical ion-exchange/reduction or solvated metal atom dispersion (SMAD) methods). In the field of zeolite catalysis, Sachtler et al..$^{12,13}$ and Moller and Bein ${ }^{14}$ have explored stabilization (anchoring) effects between unreduced intrazeolite metal ions and small catalyst clusters such as $\mathrm{Pd}$, $\mathrm{Pt}$, or $\mathrm{Rh}$.

Organometallic compounds are attractive precursors not only for surface-anchored hybrid catalysts but also for dispersed bimetallic clusters. This concept has been explored using primarily amorphous supports, ${ }^{15-19}$ and much less attention has been directed toward the encapsulation of bimetallic clusters

\footnotetext{
* Author for correspondence.

Abstract published in Advance ACS Abstracts, October 15, 1994.
}

into zeolites via organometallic precursors. ${ }^{20}$ Recently, Ichikawa et al. reported the preparation of bimetallic $\mathrm{Rh} / \mathrm{Fe}$ systems in zeolites via stepwise introduction of $\mathrm{Fe}-$ and $\mathrm{Rh}$-carbonyl species, ${ }^{21}$ while Suib et al. coadsorbed $\mathrm{Fe}_{2}(\mathrm{CO})_{9}$ and $\mathrm{CO}_{2}(\mathrm{CO})_{8}{ }^{22}$ and decomposed the intrazeolite complexes with microwave radiation.

When the catalytic centers are encapsulated in crystalline, microporous hosts such as zeolites, ${ }^{23-28}$ catalytic selectivity can be dramatically enhanced by controlling access and transport of reactants and products in the catalyst pores. Zeolites are the archetypical crystalline porous inorganic hosts with pore dimensions spanning now $3-30 \AA$ and beyond. The well-defined structure and excellent definition of the pores, ion-exchange capability, and variety of surface properties make zeolites ideal systems for imaginative host-guest chemistry aimed at the preparation of novel catalysts.

We prepare intrazeolite bimetallic clusters formed by controlled thermal decomposition of zeolite-encapsulated $\mathrm{Me}_{3} \mathrm{SnCo}-$ $(\mathrm{CO})_{4}$. This approach is related to our previous studies focused on the attachment of bimetallic GeMo, GeW, ${ }^{29}$ and $\mathrm{SnMn}^{30}$ complexes into acid zeolite hosts. The reactivity of the above $\mathrm{SnCo}$ complex and the stability of the $\mathrm{Sn}-\mathrm{Co}$ bond under different conditions have been studied. ${ }^{31}$ Substitution of carbonyl ligands with phosphines leads exclusively to monosubstituted products in the trans position to $\mathrm{Me}_{3} \mathrm{Sn}^{32}$ Heterolytic cleavage of the $\mathrm{Sn}-\mathrm{Co}$ bond and recombination are possible in certain ionizing solvents such as $\mathrm{DMF}^{33}$ and acetone. ${ }^{34}$ In the case of the sodium form of the host, initial stabilization is expected through Lewis acid/base interactions with the carbonyl ligands. This effect is known to enhance the thermal stability of carbonyl species. Our interest in the latter hybrid systems in based on their potential as highly dispersed bimetallic clusters. The $\mathrm{Sn}-\mathrm{Co}$ complex provides a convenient precursor for $\mathrm{SnCo}$ alloys made by controlled thermolysis of the encapsulated organometallic complex. This precursor route provides a lowtemperature approach to encapsulated alloy catalysts, limits 
agglomeration during cluster formation, and permits control over catalyst speciation and location.

A comprehensive combination of analytical techniques allows us to probe local structural changes at the molecular level. These techniques include EXAFS (extended X-ray absorption fine structure) spectroscopy utilizing synchrotron radiation, in-situ FT-IR coupled to thermodesorption, UV-near-IR, and porosity measurements.

\section{Experimental Section}

Sample Preparation. All manipulations were carried out under nitrogen atmosphere, and solvents were distilled from appropriate drying agents. The precursor $\mathrm{Me}_{3} \mathrm{SnCo}(\mathrm{CO})_{4}[\mathrm{mp}$ $73-74{ }^{\circ} \mathrm{C},{ }^{1} \mathrm{H}-\mathrm{NMR}: 0.63 \mathrm{ppm}$ in $\mathrm{CDCl}_{3}, J\left({ }^{119} \mathrm{Sn}-\mathrm{H}\right)=52.6$ $\left.\mathrm{Hz}, J\left({ }^{117} \mathrm{Sn}-\mathrm{H}\right)=50.6 \mathrm{~Hz}\right]$ was synthesized from the reaction between $\mathrm{Co}_{2}(\mathrm{CO})_{8}$ (freshly sublimed) and $\mathrm{Me}_{3} \mathrm{SnCl}$ in $\mathrm{MeOH}$ (predried with $\mathrm{I}_{2} / \mathrm{Mg}$ and distilled under nitrogen) following a modified reported method. ${ }^{35}$ Elemental analysis, ${ }^{1} \mathrm{H} /{ }^{13} \mathrm{C}-\mathrm{NMR}$, IR, and mass spectra all agreed well with published data. The product $\mathrm{Me}_{3} \mathrm{SnCo}(\mathrm{CO})_{4}$ was recrystallized from hexane at -50 ${ }^{\circ} \mathrm{C}$ and purified by vacuum sublimation at $35^{\circ} \mathrm{C}$ prior to use.

The structural features of $\mathrm{Me}_{3} \mathrm{SnCo}(\mathrm{CO})_{4}$ were determined by EXAFS spectroscopy at both the Co edge and Sn edge. The precursor was immobilized into degassed $\mathrm{NaY}$ zeolite (commercial PQ Valfor CBV $100\left[\mathrm{Na}_{54} \mathrm{Al}_{54} \mathrm{Si}_{138} \mathrm{O}_{384}\right] \cdot 235 \mathrm{H}_{2} \mathrm{O}$; washed in $0.1 \mathrm{M} \mathrm{NaCl}_{\mathrm{aq}}$ solution). $\mathrm{NaY}$ was degassed by calcination in oxygen for $12 \mathrm{~h}$ at $400^{\circ} \mathrm{C}$, followed by evacuation at the same temperature for $6 \mathrm{~h}\left(10^{-5} \mathrm{Torr}\right.$; heating rate $1{ }^{\circ} \mathrm{C} /$ $\mathrm{min}$ ). The dehydrated zeolites were kept in sealed vials in a glovebox prior to further treatments. An amount of $0.5 \mathrm{~g}$ of each zeolite was loaded with 1.1 molecule/supercage of $\mathrm{Me}_{3}$ $\mathrm{SnCo}(\mathrm{CO})_{4}$ in $50 \mathrm{~mL}$ of dry hexane by stirring the slurry for $18 \mathrm{~h}$ under dry nitrogen atmosphere. The slurry was filtered and washed several times with pentane. The intrazeolite samples were dried at $10^{-4}$ Torr for $1 \mathrm{~h}$. The yellowish solution was decolorized after impregnation, and $\mathrm{X}$-ray fluorescence measurements showed the expected loading levels $(1.0 \pm 0.2$ molecule per supercage); thus, loading was nearly quantitative. Dry powder samples were flame-sealed under vacuum in glass ampules for storage.

EXAFS samples for thermal stability studies were prepared by heating $0.5 \mathrm{~g}$ batches of loaded zeolites in a tube furnace between 90 and $300{ }^{\circ} \mathrm{C}$ under $10^{-5}$ Torr vacuum. The temperature was ramped up at a heating rate of $1^{\circ} \mathrm{C} / \mathrm{min}$ to the desired temperature and kept constant for $6 \mathrm{~h}$. The powdered samples were mixed with a molten, degassed 1:1 mixture of octadecane and eicosane at $30-35{ }^{\circ} \mathrm{C}$, and the encapsulated samples were packaged in EXAFS sample holders, sealed with Kapton tape, and kept under nitrogen until EXAFS measurements were performed.

Characterization. FTIR data of thin zeolite dispersions (from pentane slurry) on $\mathrm{Si}$ wafers in a steel cell were taken with a Mattson Polaris spectrometer at $4 \mathrm{~cm}^{-1}$ resolution. The samples were evacuated with a molecular sieve/turbomolecular pump combination until the total pressure (including $\mathrm{H}_{2}$ ) was $<10^{-6}$ Torr prior to any treatment. Up to five mass fragments could be monitored as a function of time/temperature in the TPD-MS experiment. Zeolite samples were heated at $2{ }^{\circ} \mathrm{C} /$ min while FTIR and mass spectra were monitored. Electronic spectra were obtained in the diffuse reflectance mode with an integrating sphere in an Hitachi $3501 \mathrm{UV}-$ near-IR spectrometer $\left(\mathrm{BaSO}_{4}\right.$ reference). Porosity was studied by nitrogen sorption in a Coulter Omnisorb 100. Powder X-ray diffraction data were obtained with a Scintag XDS2000 and a Siemens D500

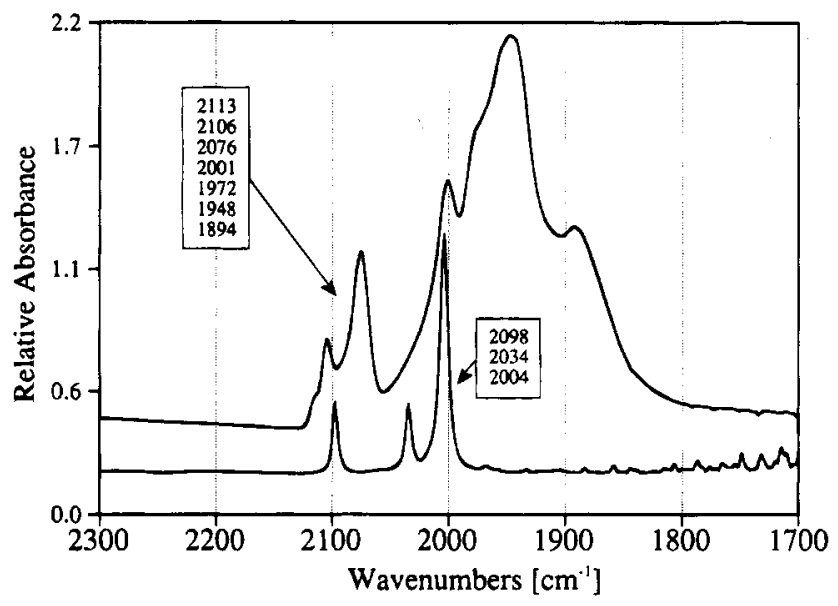

Figure 1. Infrared spectra of the carbonyl stretching region of $\mathrm{Me}_{3}$ $\mathrm{SnCo}(\mathrm{CO})_{4}$ in $\mathrm{NaY}(\mathrm{A})$ compared with the precursor in fluorolube mull (B).

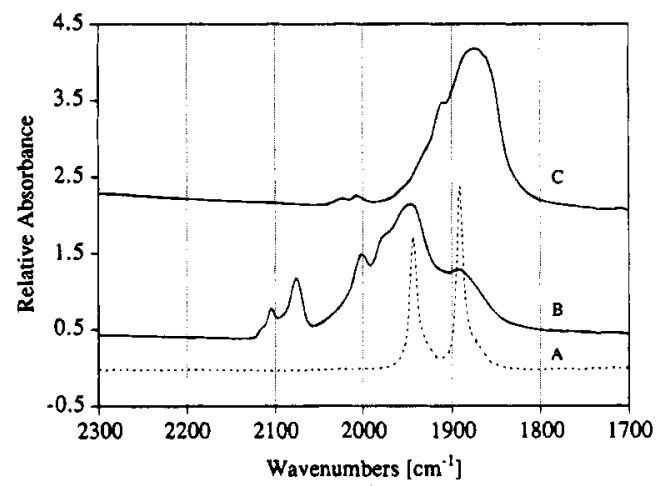

Figure 2. Reactivity of $\mathrm{Me}_{3} \mathrm{SnCo}(\mathrm{CO})_{4}$ with $\mathrm{PMe}_{3}$ : (A) $\mathrm{Me}_{3} \mathrm{SnCo}$ (CO) $3\left(\mathrm{PMe}_{3}\right)$ synthesized in solution; (B) $\mathrm{Me}_{3} \mathrm{SnCo}(\mathrm{CO})_{4}$ in zeolite $\mathrm{NaY}$; (C) $\mathrm{Me}_{3} \mathrm{SnCo}(\mathrm{CO})_{4}$ in zeolite $\mathrm{NaY}$ treated with $\mathrm{PMe}_{3}$.

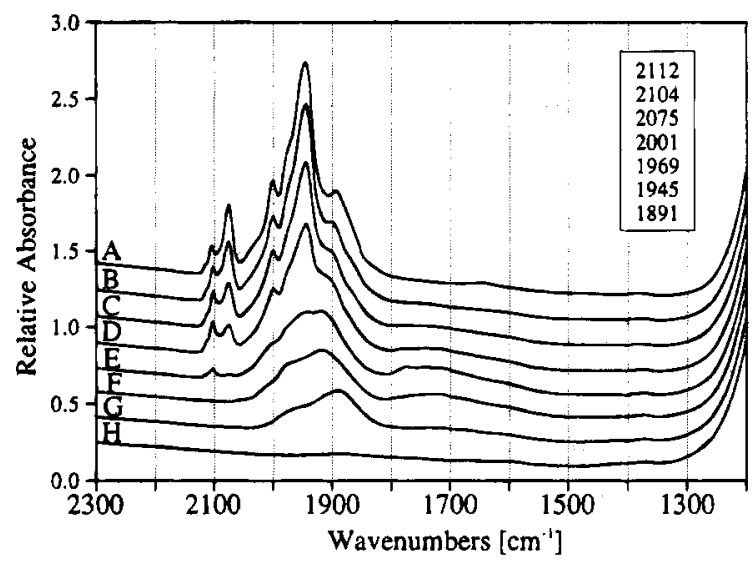

Figure 3. In-situ FTIR spectra of $\mathrm{Me}_{3} \mathrm{SnCo}(\mathrm{CO})_{4}$ in the $\mathrm{NaY}$ host under vacuum: (A) 30, (B) 110, (C) 130, (D) 140, (E) 150, (F) 170, (G) 210 , and $(\mathrm{H}) 300^{\circ} \mathrm{C}$. Heating rate $2^{\circ} \mathrm{C} / \mathrm{min}$.

instrument. X-ray fluorescence provided elemental composition of the samples ( $\mathrm{Sn}, \mathrm{Co})$.

EXAFS measurements were carried out at NSLS (Brookhaven National Laboratories) at beamline X-11A with a stored energy of $2.5 \mathrm{GeV}$ and ring currents between 100 and $200 \mathrm{~mA}$. Data were collected at the Co $\mathrm{K}$ edge $(7709 \mathrm{eV})$ and the Sn $\mathrm{K}$ edge $(29000 \mathrm{eV})$. The experiments were performed at about $100 \mathrm{~K}$ in transmission using a double-crystal $\mathrm{Si}(311)$ monochromator. The EXAFS data were analyzed using standard procedures, as described in a previous article. ${ }^{30}$

At the cobalt edge, the $\mathrm{C}$ and $\mathrm{O}$ components of the carbonyl ligands were fitted with the respective contribution in $\mathrm{Ni}(\mathrm{CO})_{4}$ 


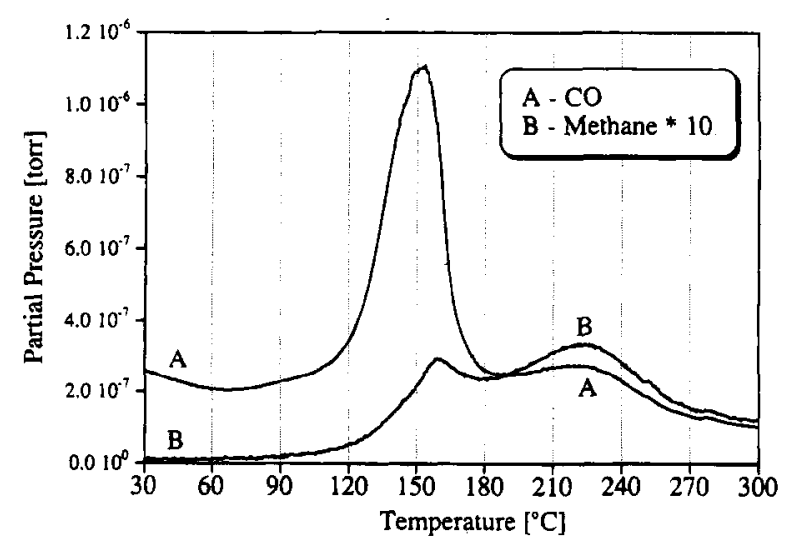

Figure 4. TPD/MS data of $\mathrm{Me}_{3} \mathrm{SnCo}(\mathrm{CO})_{4}$ in the $\mathrm{NaY}$ host, heated under vacuum at a heating rate of $2{ }^{\circ} \mathrm{C} / \mathrm{min}$ : (A) $\mathrm{CO}(\mathrm{m} / \mathrm{e}=28)$; (B) $\mathrm{CH}_{4}(m / e=16)$. The methane signal is $10 \times$ enlarged.

TABLE 1: Crystallographic Data of Reference Compounds

\begin{tabular}{lllrl}
\hline \multicolumn{1}{c}{ reference } & atom pair & $R(\AA)$ & $N$ & ref \\
\hline $\mathrm{Ni}(\mathrm{CO})_{4}$ & $\mathrm{Ni}-\mathrm{CO}$ & 1.827 & 4 & \\
& $\mathrm{Ni}-\mathrm{CO}$ & 2.942 & 4 & \\
$\mathrm{Me}_{3} \mathrm{SnMn}(\mathrm{CO})_{5}$ & $\mathrm{Sn}-\mathrm{Mn}$ & 2.67 & 1 & 38 \\
& $\mathrm{Sn}-\mathrm{C}$ & 2.16 & 2 & \\
& $\mathrm{Sn}-\mathrm{C}$ & 2.06 & 1 & \\
Co foil (hcp) & $\mathrm{Co}-\mathrm{Co}$ & 2.514 & 12 & \\
& $\mathrm{Co}-\mathrm{Co}$ & 3.555 & 6 & \\
Sn foil (white $\mathrm{Sn})$ & $\mathrm{Sn}-\mathrm{Sn}$ & 3.02 & 4 & 39 \\
& $\mathrm{Sn}-\mathrm{Sn}$ & 3.18 & 2 & \\
& $\mathrm{Sn}-\mathrm{Sn}$ & 3.77 & 4 & \\
$\mathrm{Sn}\left(\mathrm{CH}_{3}\right)_{4}$ & $\mathrm{Sn}-\mathrm{C}$ & 2.134 & 4 &
\end{tabular}

The metal-metal bond ( $\mathrm{Co}-\mathrm{Sn})$ is obscured by the carbonyl ligands. However, after subtracting the calculated $\mathrm{CO}$ backscattering from the original data, the remaining amplitude function is similar to a heavier metal backscatterer. The latter contribution was used as internal reference for the zeolite samples for the metal-metal bond and was set to coordination number $N=1.0$ and distance $R=2.67 \AA$. The distance was obtained from Sn EXAFS data where the bond to Co is more clearly saparated. A combined fit of the carbon and metal shells gave the final results. The Sn EXAFS data were fitted with $\mathrm{SnMe}_{4}$ and $\mathrm{Me}_{3} \mathrm{SnMn}(\mathrm{CO})_{5}$ as reference for the metal-metal bond (no X-ray structure is available for $\mathrm{Me}_{3} \mathrm{SnCo}(\mathrm{CO})_{4}$ ); see Table 1.

\section{Results and Discussion}

$\mathrm{Me}_{3} \mathrm{SnCo}(\mathrm{CO})_{4}$ in $\mathrm{NaY}$ Zeolite. In-situ infrared spectroscopy coupled with temperature-programmed desorption was used to explore the complex-surface interactions and the thermal stability of the intrazeolite complex. The desorption of volatile byproducts such as methane or carbon monoxide was recorded in situ as a function of time/temperature.

If the carbonyl stretching region of the precursor (in fluorolube: $2098,2035,2004 \mathrm{~cm}^{-1}$; in hexane: 2083,2020 , and $1988 \mathrm{~cm}^{-1}$ ) is compared with that of the complex in $\mathrm{NaY}$ zeolite, drastic changes are observed (Figure 1). The number of bands increases from the three bands of the precursor (consistent with trigonal pyramidal structure) to at least six, and the major intensity shifts to lower energy. Three IR-active $\mathrm{CO}$ bands are predicted for $C_{3 v}$ symmetry $\left(2 \mathrm{~A}_{1}+\mathrm{E}\right.$, at lowest energy) and four bands for $C_{s}$ symmetry $\left(3 \mathrm{~A}^{\prime}+\mathrm{A}^{\prime \prime}\right)$, where the degenerate $E$ mode is split. ${ }^{35,36}$ This effect is now wellknown for carbonyl complexes in zeolites (e.g., refs 29 and 30) and is indicative of association of the carbonyl ligand(s) with the Lewis acidic sodium cations, i.e., $\mathrm{Co}-\mathrm{CO}-\mathrm{Na}^{+}$, and the resulting distortion of the carbonyl moiety with original $C_{3 \mathrm{v}}$
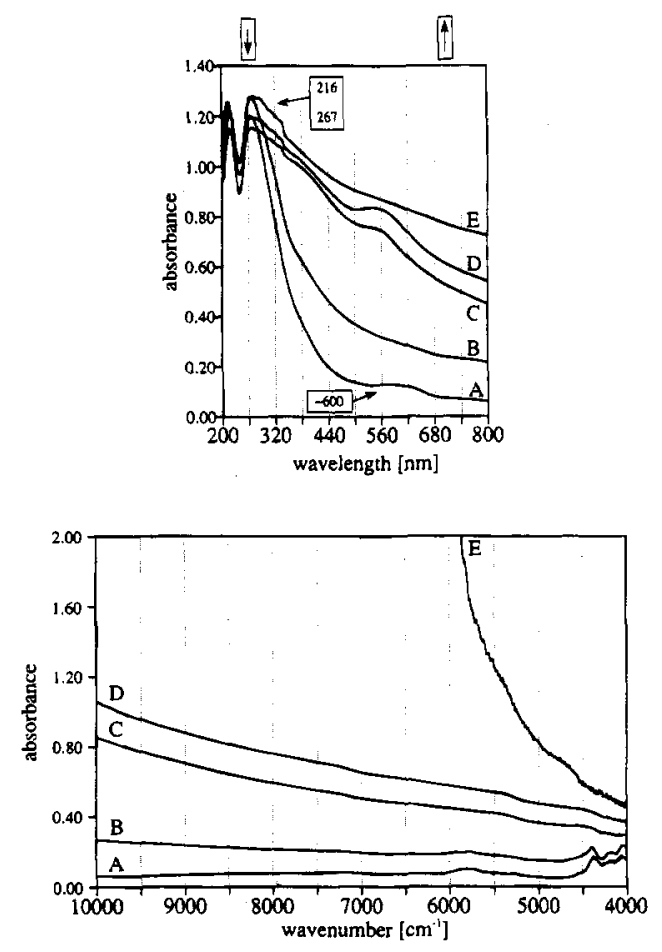

Figure 5. UV (top) and near-IR spectra (bottom) of $\mathrm{Me}_{3} \mathrm{SnCo}(\mathrm{CO})_{4}$ in $\mathrm{NaY}$ after different heat treatments under vacuum: (A) 30, (B) 90 , (C) 160, (D) 190 , and (E) $300^{\circ} \mathrm{C}$.

symmetry. Because one type of complex can have no more than four bands when distorted, there must be at least two types of species present. The bands at 2076, 2001, 1948, and 1894 $\mathrm{cm}^{-1}$ simultaneously diminish in intensity on heating (see below); thus, they are assigned to one weakly bound species, while the more stable set of bands, including a high-energy vibration at $2106 \mathrm{~cm}^{-1}$, survives up to over $170^{\circ} \mathrm{C}$.

Reactivity of the Sn-Co Precursor in NaY Zeolite. The reactivity of the $\mathrm{SnCo}$ complex in $\mathrm{NaY}$ with trimethylphosphine was studied in comparison to the reactivity of the unsupported SnCo precursor in solution. The solution reaction was carried out under nitrogen by stirring 1:5 molar ratios of complex:PMe for $12 \mathrm{~h}$ at $70^{\circ} \mathrm{C}$ in THF. After isolation of the product, it shows two strong infrared CO stretching modes (1943 and 1891 $\mathrm{cm}^{-1}$ in hexane; 1936 and $1880 \mathrm{~cm}^{-1}$ in THF), compared with the three modes of the precursor at 2083,2020 , and $1988 \mathrm{~cm}^{-1}$. This IR pattern is typical for increased $\pi$-back-bonding on substitution of carbonyls with phosphine and, together with NMR data, is consistent with the exclusive formation of monosubstituted $\mathrm{Me}_{3} \mathrm{SnCo}(\mathrm{CO})_{3}\left(\mathrm{PMe}_{3}\right)$ (Figure 2).

The reaction of the precursor in $\mathrm{NaY}$ with $\mathrm{PMe}_{3}$ was carried out in a Schlenk flask. A vial with a 3-fold excess of the phosphine was connected to the evacuated flask charged with $\mathrm{SnCo}$ zeolite. The phosphine was heated to $80^{\circ} \mathrm{C}$ and was then allowed to expand into the flask. The flask was closed and heated for $48 \mathrm{~h}$ at $70^{\circ} \mathrm{C}$. The sample was cooled to room temperature (RT), evacuated at $60^{\circ} \mathrm{C}$ for $2 \mathrm{~h}$ to remove excess phosphine, then washed thoroughly with pentane, and evacuated. (No reaction was observed when the SnCo-loaded zeolite was stirred in a $\mathrm{PMe}_{3}$ /hexane slurry at RT for $24 \mathrm{~h}$ ). The CO stretch pattern shows drastic changes after this reaction. The original set of bands in $\mathrm{NaY}$ (major peaks at 2076, 2001, and $1948 \mathrm{~cm}^{-1}$ ) is replaced by a broader peak at 1873 with a shoulder at 1911 $\mathrm{cm}^{-1}$. This red shift is consistent with phosphine substitution and increased $\pi$-back-bonding, as in the solution reaction (Figure 2). These observations demonstrate that the intrazeolite complex $\mathrm{Me}_{3} \mathrm{SnCo}(\mathrm{CO})_{4}$ can react with a phosphine ligand diffusing into 

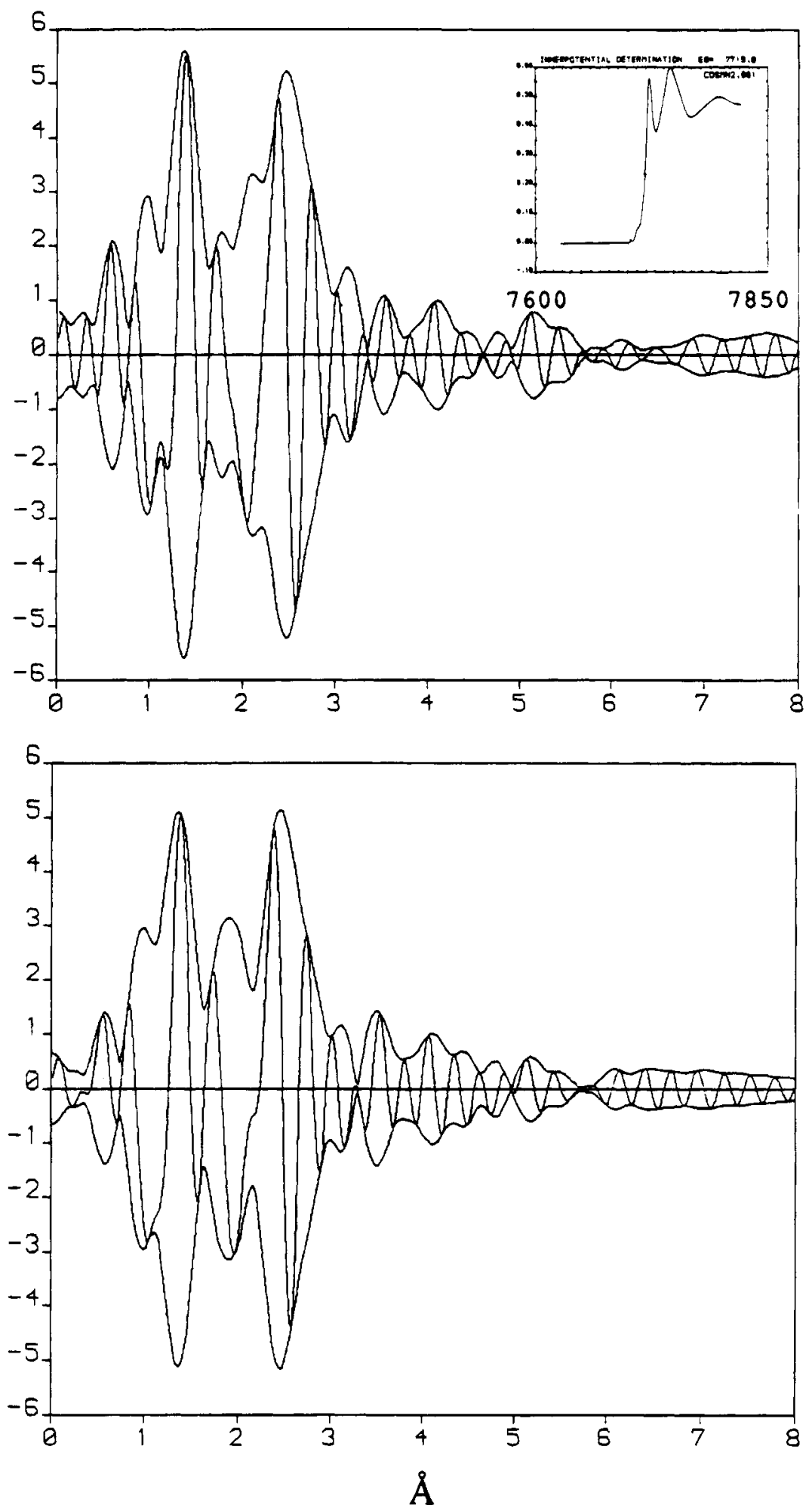

Figure 6. Fourier-transformed EXAFS data of $\mathrm{Me}_{3} \mathrm{SnCo}(\mathrm{CO})_{4}$ in $\mathrm{NaY}$ at different treatment temperatures, Co edge: top, $30{ }^{\circ} \mathrm{C}$; bottom, $90{ }^{\circ} \mathrm{C}$ (abscissa: distance in $\AA$ ). Insert: edge structure, $7600-7850 \mathrm{eV}\left(k^{3}\right.$ weighted, range $\left.2.3-12.1 \AA^{-1}\right)$.

the pore system from the gas phase. Thermal desorption studies of the phosphine-substituted product in the NaY host $\left(3{ }^{\circ} \mathrm{C} /\right.$ min heating rate) show phosphine evolution at $100{ }^{\circ} \mathrm{C}$, due to desorption of excess $\mathrm{PMe}_{3}$, and complex decomposition with phosphine and $\mathrm{CO}$ evolution at about $150-170{ }^{\circ} \mathrm{C}$. The phosphine ligand thus stabilizes the complex.

In-situ FTIR-TPD experiments with the SnCo precursor in $\mathrm{NaY}$ show a slow decrease of the above-mentioned "quartet of bands" when heating to about $150{ }^{\circ} \mathrm{C}$ (Figure 3). Drastic changes occur between 150 and $210^{\circ} \mathrm{C}$ where most of the $\mathrm{CO}$ intensity is lost, peaks are broadened, and a shift to lower energy is observed. A weak broad band at $c a .1730 \mathrm{~cm}^{-1}$ indicates the formation of bridged carbonyl ligands after drastic rearrangements have taken place. TPD/MS spectra of this system show a first peak in $\mathrm{CO}$ evolution at $130-170^{\circ} \mathrm{C}$, followed by a smaller one at $220^{\circ} \mathrm{C}$ (Figure 4). These observations are explained with the loss of carbonyl ligands from $\mathrm{Me}_{3} \mathrm{SnCo}-$ $(\mathrm{CO})_{4}$ and formation of metal carbonyl clusters in the zeolite cages. The second $\mathrm{CO}$ peak is assigned to the decarbonylation of these clusters. Methane evolution above $120^{\circ} \mathrm{C}$ coincides with the decarbonylation and rearrangement of the $\mathrm{Sn}-\mathrm{Co}$ structure.

Electronic absorption spectra of $\mathrm{Me}_{3} \mathrm{SnCo}(\mathrm{CO})_{4}$ in $\mathrm{NaY}$ show well-resolved bands at 216 and $267 \mathrm{~nm}$; these are probably due 


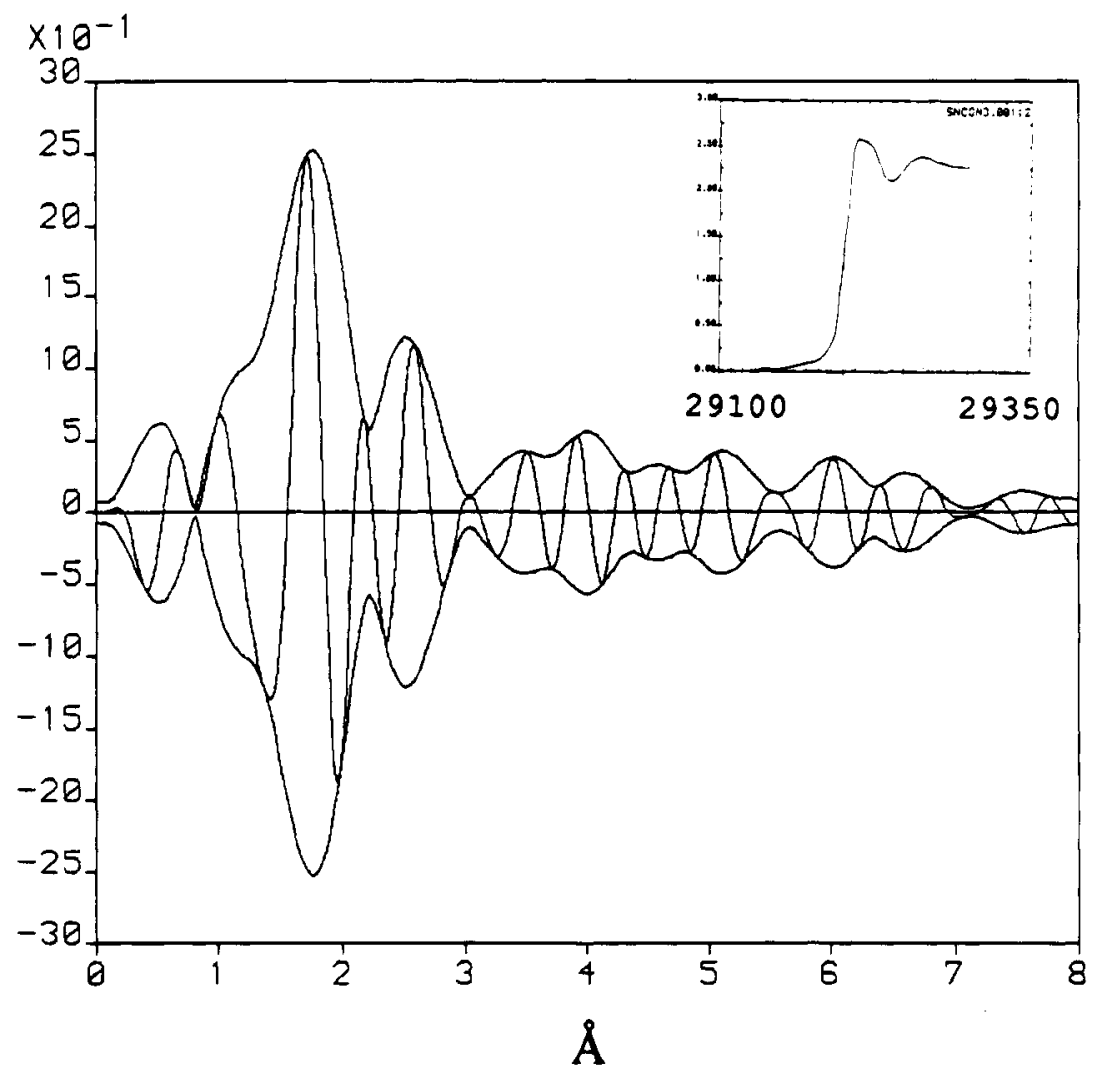

Figure 7. Fourier-transformed EXAFS data of $\mathrm{Me}_{3} \mathrm{SnCo}(\mathrm{CO})_{4}$ in $\mathrm{NaY}$ heated at $90{ }^{\circ} \mathrm{C}$, Sn edge. Insert: edge structure, $29100-29350 \mathrm{eV}$.

TABLE 2: Structural Results Derived from EXAFS Data

\begin{tabular}{llllrr}
\hline sample & atom pair & $N^{a}$ & $R / \AA^{b}$ & $\Delta \sigma^{2} / \AA^{2} c$ & $\Delta E / \mathrm{eV}^{d}$ \\
\hline $\mathrm{RT}$ & $\mathrm{Co}-\mathrm{CO}$ & 4.1 & 1.79 & 0.0039 & -0.8 \\
& Co-CO & 4.2 & 2.91 & 0.0016 & 1.1 \\
& $\mathrm{Co}-\mathrm{Sn}$ & $I$ & 2.67 & -0.0006 & -3.9 \\
& $\mathrm{Sn}-\mathrm{C}$ & 2.8 & 2.10 & -0.004 & -0.1 \\
& $\mathrm{Sn}-\mathrm{Co}$ & 1.4 & 2.67 & -0.0013 & -4.9 \\
$90{ }^{\circ} \mathrm{C}$ & $\mathrm{Co}-\mathrm{CO}$ & 4.0 & 1.80 & 0.0044 & -2.1 \\
& $\mathrm{Co}-\mathrm{CO}$ & 3.7 & 2.91 & 0.001 & 0.6 \\
& $\mathrm{Co}-\mathrm{Sn}$ & 1 & 2.67 & -0.0018 & -4.1 \\
& $\mathrm{Sn}-\mathrm{C}$ & 3.1 & 2.12 & 0.0003 & -1.4 \\
& $\mathrm{Sn}-\mathrm{Co}$ & 1.0 & 2.64 & -0.0017 & -2.8 \\
$160{ }^{\circ} \mathrm{C}$ & $\mathrm{Co}-\mathrm{CO}$ & 0.6 & 1.86 & -0.0052 & -0.2 \\
& $\mathrm{Co}-\mathrm{CO}$ & 1.7 & 2.83 & -0.0008 & 2.5 \\
& $\mathrm{Co}-\mathrm{Co}$ & 1.4 & 2.45 & 0.0030 & 11.3 \\
$190^{\circ} \mathrm{C}$ & $\mathrm{Co}-\mathrm{CO}$ & 0.4 & 1.91 & -0.0042 & -2.7 \\
& $\mathrm{Co}-\mathrm{CO}$ & 1.7 & 2.85 & -0.0008 & -0.3 \\
& $\mathrm{Co}-\mathrm{Co}$ & 1.4 & 2.44 & 0.0011 & 12.3 \\
& $\mathrm{Sn}-\mathrm{O} / \mathrm{C}$ & 1.3 & 2.18 & -0.0006 & -11.4 \\
& $\mathrm{Sn}-\mathrm{Co}$ & 2.6 & 2.47 & 0.0025 & 10.0 \\
$300^{\circ} \mathrm{C}$ & $\mathrm{Co}-\mathrm{Co}$ & 2.8 & 2.46 & 0.0044 & 13.1 \\
& $\mathrm{Co}-\mathrm{Sn}$ & 1.8 & 2.72 & 0.0027 & 15 \\
& $\mathrm{Co}-\mathrm{Co}$ & 1.3 & 3.45 & 0.0046 & 10.4 \\
& $\mathrm{Sn}-\mathrm{Sn}$ & 0.7 & 2.95 & -0.0046 & -1.0 \\
& $\mathrm{Sn}-\mathrm{Co}$ & 2.8 & 2.68 & 0.0055 & 6.7 \\
& $\mathrm{Sn}-\mathrm{Sn}$ & 2.2 & 3.71 & -0.0001 & 7.7
\end{tabular}

${ }^{a}$ Coordination number. ${ }^{b}$ Bond distance. ${ }^{c}$ Static disorder. ${ }^{d}$ Inner potential.

to charge-transfer bands (Figure 5). The thermal decomposition results in remarkable changes in the UV-near-IR spectra. The optical absorption increases dramatically, supporting the formation of nanometer size metallic $\mathrm{Sn} / \mathrm{Co}$ clusters as discussed below.

Pore volume changes determined from nitrogen sorption data ( $t$-plot evaluation) illustrate the successive decomposition of the intrazeolite complexes. The micropore volume of the $\mathrm{NaY}$ host $(0.240 \mathrm{~mL} / \mathrm{g})$ reduces to $0.10 \mathrm{~mL} / \mathrm{g}$ on adsorption of the $\mathrm{SnCo}$ complex. Heating to $90^{\circ} \mathrm{C}$ does not change the pore volume, confirming the stability of the intrazeolite complex up to that temperature. However, on heating to $160^{\circ} \mathrm{C}$ (pore volume 0.16 $\mathrm{mL} / \mathrm{g})$ and $190^{\circ} \mathrm{C}(0.17 \mathrm{mgL} / \mathrm{g})$, decarbonylation leads to a significant increase in free space. The accessible micropore volume at room temperature shows that reactants such as phosphines have access to the intrazeolite complex. We note that the size of the nitrogen probe (kinetic diameter $3.6 \AA$ ) could lead to a low estimate of the free space in zeolite cages containing other species.

EXAFS. The study of the complex in NaY zeolite was complemented with comprehensive EXAFS (extended X-ray absorption fine structure) characterization of the reaction products at different temperatures. The EXAFS data analysis in conjunction with the other results allow us to conclude the following: The bimetallic complex remains intact when adsorbed into the dry sodium form (Co- $\mathrm{CO}, 4.1$ ligands at 1.79 $\AA$; Co-CO, 4.2 at 2.91 $\AA$ ) (Figure 6, Tables 1 and 2). The Co edge shape is typical for a carbonyl complex. The metal bond is obscured by the $\mathrm{CO}$ backscattering but is clearly seen at the Sn edge. The tin coordination sphere is consistent with three methyl groups remaining $\left(\mathrm{Sn}-\mathrm{C}_{2.8}\right.$ at $2.10 \AA$ ). The $\mathrm{Sn}-\mathrm{Co}$ bond can also be detected at a distance of $2.67 \AA$. The coordination numbers of the metal bond in room temperature samples and in those heated to $90^{\circ} \mathrm{C}$ vary between 1.4 and 0.8 due to limits in fit quality. A minor, unidentified second component overlaps with the metal peak. On heating in vacuum, the complex is stable up to about $90^{\circ} \mathrm{C}$, as determined from the (almost unchanged) cobalt and tin coordination spheres (Figures 6 and 7). The Sn-cobalt backscattering can be clearly seen at about $2.5 \AA$ (not phase-corrected in the Fouriertransformed EXAFS function (Figure 7). No outer-shell peaks typical for framework attachment of tin are obvious up to this temperature. The tin edge shape also indicates the continued presence of methyl ligands at $90^{\circ} \mathrm{C}$. Between 90 and $160^{\circ} \mathrm{C}$ carbonyl ligands begin to desorb, as indicated by the visible loss of $\mathrm{CO}$ backscattering intensity in the Co EXAFS. A Co$\mathrm{CO}$ population of at most 1.7 at $2.83 \AA$ can still be detected at $160^{\circ} \mathrm{C}$, but the Co-edge shape and its shift to lower energy 

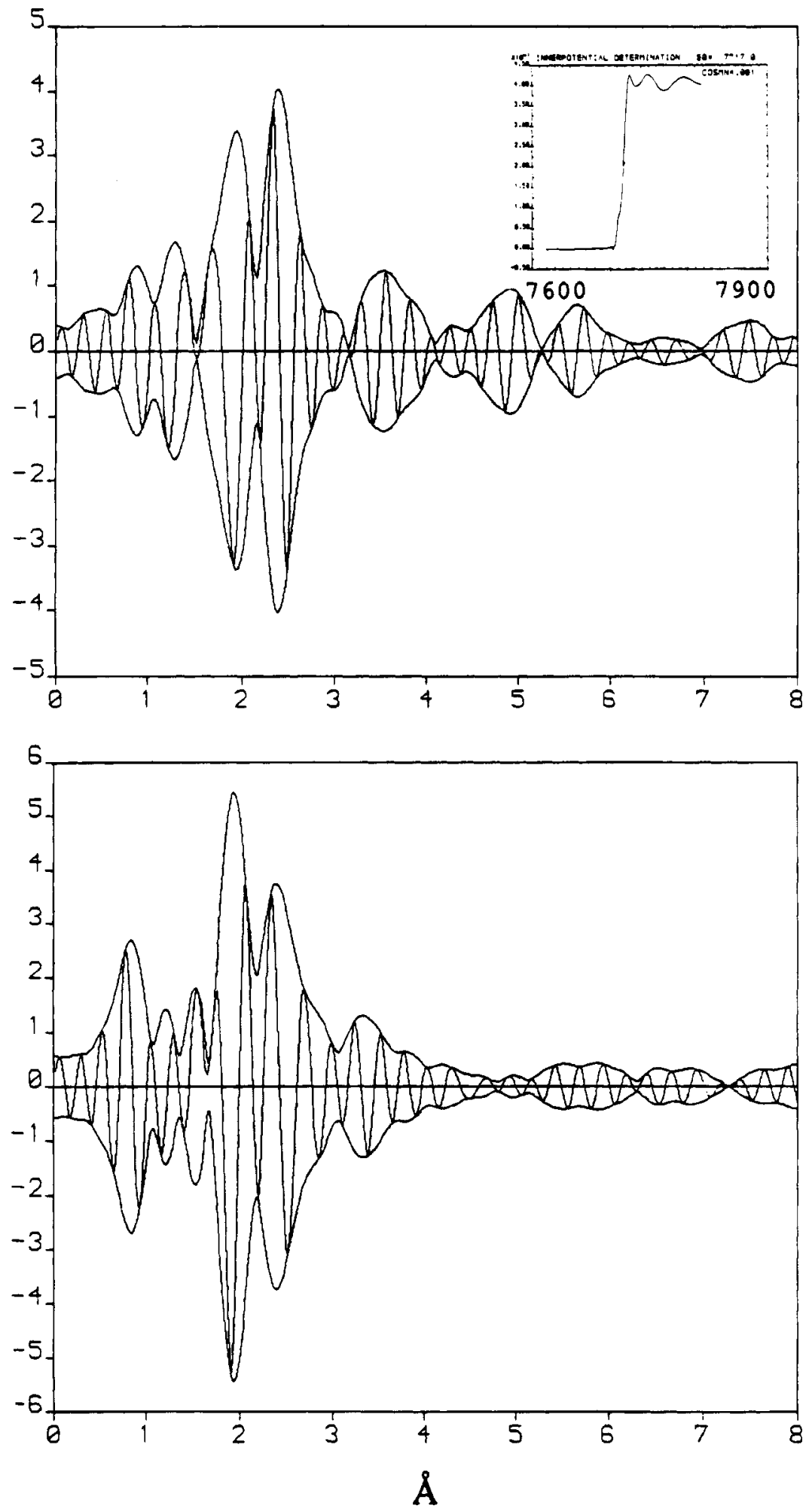

Figure 8. Fourier-transformed EXAFS data of $\mathrm{Me}_{3} \mathrm{SnCo}(\mathrm{CO})_{4}$ in $\mathrm{NaY}$ at different treatment temperatures, Co edge: top, $160{ }^{\circ} \mathrm{C}$; bottom, $190{ }^{\circ} \mathrm{C}$. Insert: edge structure, $7600-7900 \mathrm{eV}$.

clearly show the beginning formation of metal clusters (Figure 8). At $190^{\circ} \mathrm{C}$, the tin coordination includes an increased $\mathrm{Sn}-$ $\mathrm{Co}_{2.6}$ population at $2.47 \AA$, the first indication of alloy cluster growth (Figure 9). These observations confirm the IR/TPDMS results. Loss of methane is observed at about $160^{\circ} \mathrm{C}$ (see Figure 4 for mass spectrometric data). Beyond this temperature, the EXAFS data show complete conversion into extremely small cobalt/tin clusters, at $300{ }^{\circ} \mathrm{C}$ with an average first-shell $\mathrm{Co}-$ Co coordination of 2.8 (at $2.46 \AA$ ), an average $\mathrm{Sn}-\mathrm{Sn}$ coordination of 0.7 at $2.95 \AA$, and with only one small outer shell in the cluster $\left(\mathrm{Co}-\mathrm{Co}_{1.3}\right.$ at $3.45 \AA ; \mathrm{Sn}-\mathrm{Sn}_{2.2}$ at $3.71 \AA$ ) (Figures 9 and 10). The bond distances are contracted compared to bulk metal, a common effect with extremely small clusters (compare with Table 1). The Co edge is shifted to lower energy, and its structure resembles that of metallic cobalt. Similarly, the tin edge now resembles that of metallic tin. No carbon or oxygen coordination is observed at the tin edge, demonstrating complete removal of the methyl ligands and absence of welldefined bonding to the zeolite framework. Importantly, the EXAFS of both metals cannot be fitted with exclusive coordination only to the same metal but requires contributions from the other metal. This implies formation of nanometer size alloys in the zeolite cages $\left(\mathrm{Co}-\mathrm{Sn}_{1.8}\right.$ at $2.72 \AA, \mathrm{Sn}-\mathrm{Co}_{2.8}$ at $2.68 \AA$ ).

The above coordination numbers correspond to alloy clusters 

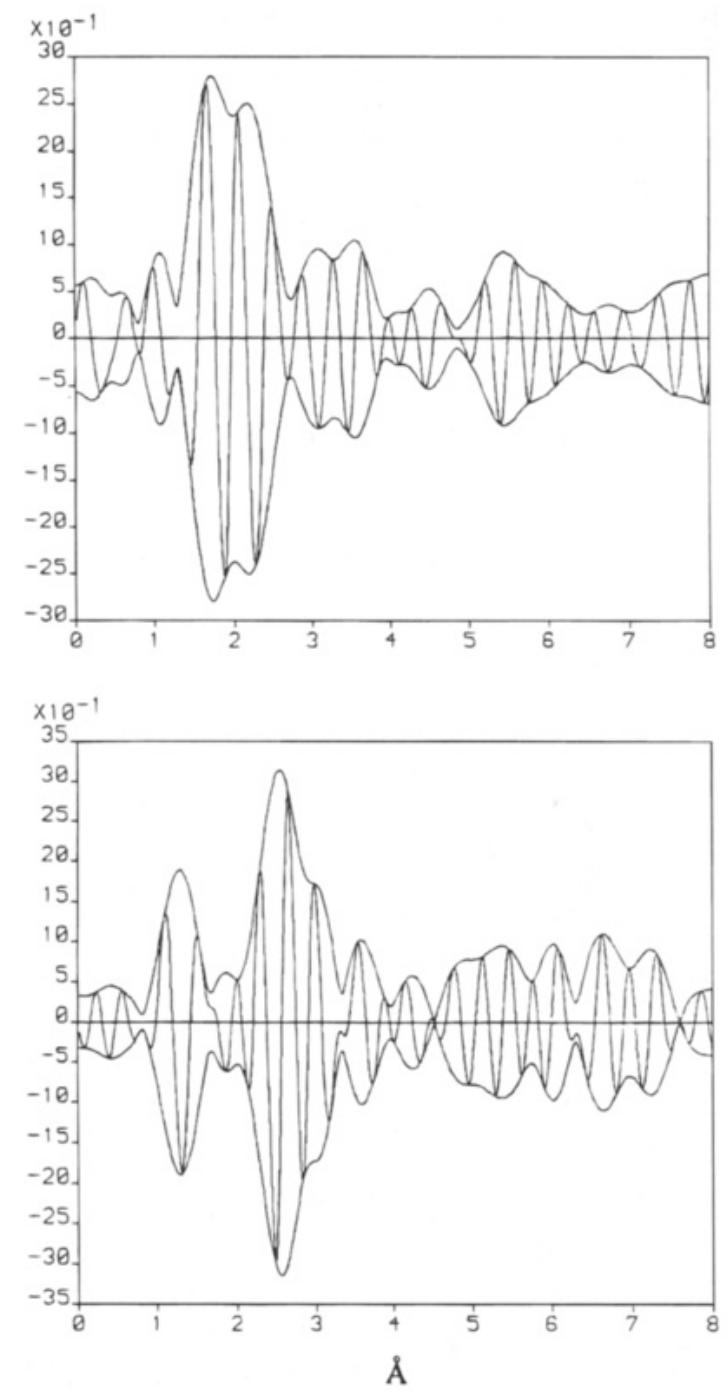

Figure 9. Fourier-transformed EXAFS data of $\mathrm{Me}_{3} \mathrm{SnCo}(\mathrm{CO})_{4}$ in $\mathrm{NaY}$ at different treatment temperatures, Sn-edge: top, $190{ }^{\circ} \mathrm{C}$; bottom, 300 ${ }^{\circ} \mathrm{C}$.

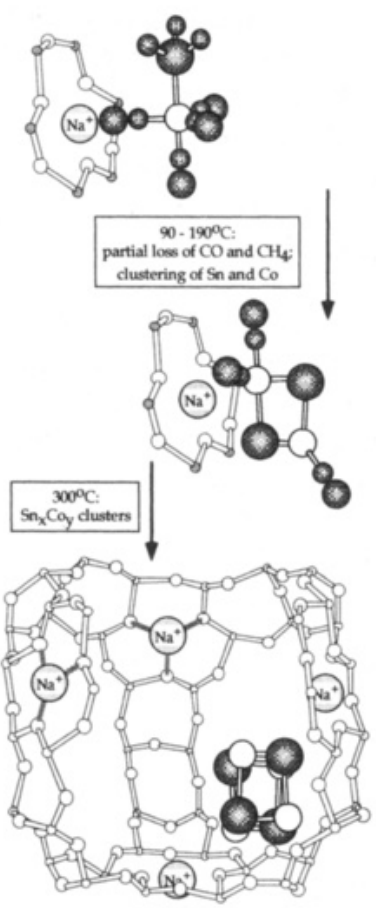

Figure 11. Proposed intrazeolite chemistry of $\mathrm{Me}_{3} \mathrm{SnCo}(\mathrm{CO})_{4}$ in zeolite NaY.

containing about 10 atoms. Because a size distribution is likely, a unique structural model of the clusters cannot be proposed on the basis of EXAFS data.

\section{Conclusions}

The combination of EXAFS data and in-situ FTIR coupled with TPD-MS measurements discussed above provides a comprehensive picture of the intrazeolite structure and chemistry of $\mathrm{Me}_{3} \mathrm{SnCo}(\mathrm{CO})_{4}$. An overview is given in Figure 11 .

In the "neutral" environment of the NaY host, the precursor is physically adsorbed into the zeolite cages without further

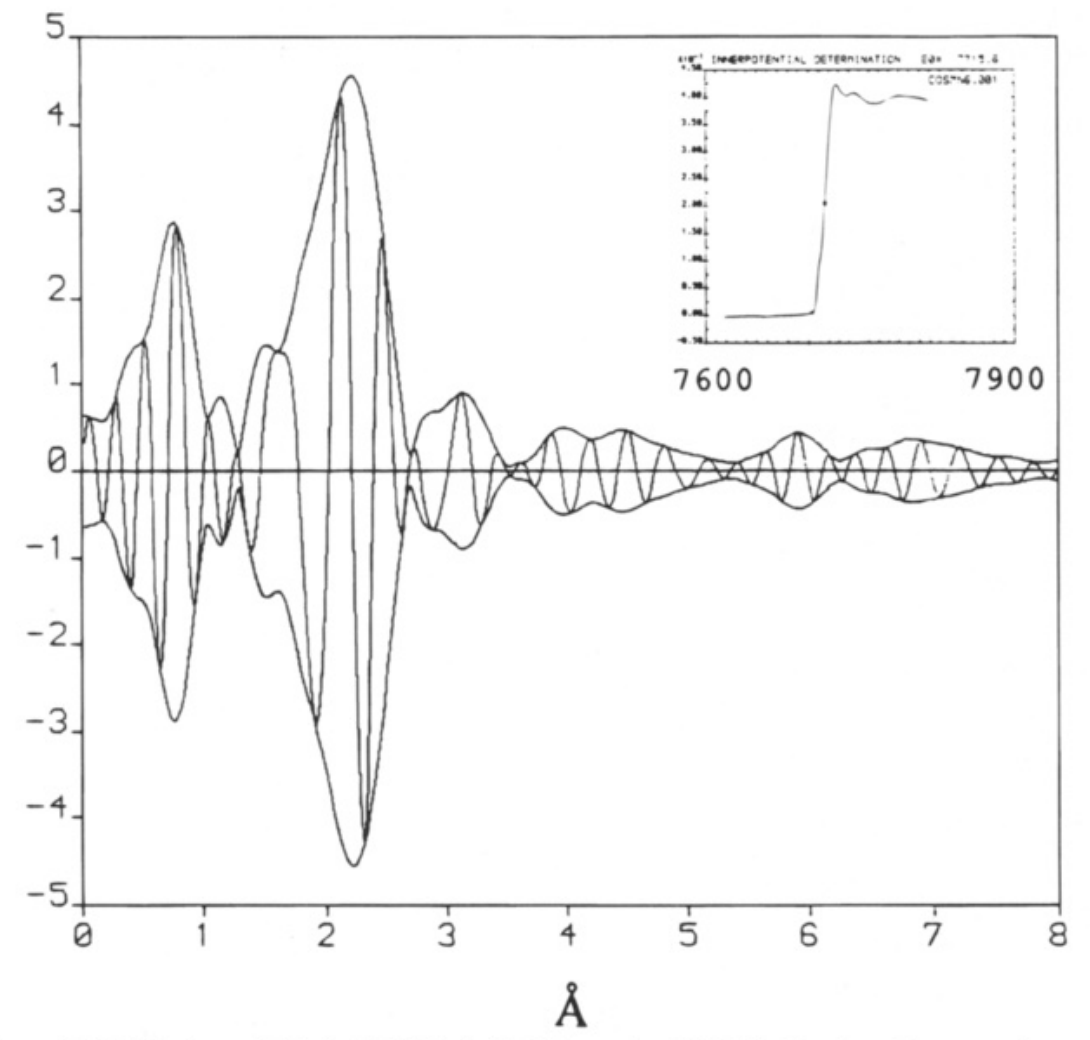

Figure 10. Fourier-transformed EXAFS data of $\mathrm{Me}_{3} \mathrm{SnCo}(\mathrm{CO})_{4}$ in $\mathrm{NaY}$ heated at $300{ }^{\circ} \mathrm{C}$, Co-edge. Insert: edge structure, $7600-7900 \mathrm{eV}$. 
chemical reaction. As found with other carbonyl compounds, the $\mathrm{Na}^{+}$ions in the zeolite framework interact with the $\mathrm{CO}$ ligands at the oxygen end, ${ }^{37}$ resulting in symmetry changes of the $\mathrm{Co}(\mathrm{CO})_{4}$ moiety. The weakly adsorbed species are preferentially removed from the zeolite with increasing temperature. The remaining complex decomposes between 90 and $160^{\circ} \mathrm{C}$ by loss of $\mathrm{CO}$ ligands and rearrangement of the $\mathrm{Sn}-\mathrm{Co}$ structure. Tin-cobalt alloy cluster species of unknown structure are formed above about $160^{\circ} \mathrm{C}$. These clusters are surprisingly stable against sintering; even at $300^{\circ} \mathrm{C}$ their average coordination numbers suggest a cluster size of only about 10 atoms.

The intrazeolite complex in $\mathrm{NaY}$ undergoes carbonyl substitution with $\mathrm{PMe}_{3}$ at the cobalt atom. The thermal stability of these encapsulated organometallic and alloy species permits further studies on their chemical reactivity and potential catalytic activity.

Acknowledgment. The authors thank Professor D. C. Koningsberger for software for EXAFS data analysis. Funding from the U.S. Department of Energy for this work is gratefullyacknowledged. The operational funds for NSLS beamline $\mathrm{X}-11 \mathrm{~A}$ are supported by DOE Grant DE-AS0580ER10742.

\section{References and Notes} 1986.

1) Catalytic Hydrogenation; Cerveny, L., Ed.; Elsevier: Amsterdam,

(2) (a) Sachtler, W. M. H. J. Mol. Catal. 1984, 25, 1. (b) Sachtler W. M. H. Catal. Rev.-Sci. Eng. 1976, 14, 193.

(3) Augustine, S. M.; Sachtler, W. M. H. J. Catal. 1987, 106, 417.

(4) den Hartog, A. J.; Rek, P. J. M.; Ponec, V. J. Chem. Soc., Chem. Commun. 1988, 1470.

(5) Meitzner, G.; Via, G. H.; Lytle, F. W.; Fung, S. C.; Sinfelt, J. H. J. Phys. Chem. 1988, 92, 2925.

(6) (a) Sinfelt, J. H. Bimetallic Catalysts-Discoveries, Concepts and Applications; Wiley: New York, 1983. (b) Sinfelt, J. H. Acc. Chem. Res. 1987, $20,134$.

(7) Tan, B. J.; Klabunde, K. J.; Tanaka, T.; Kanai, H.; Yoshida, S. J. Am. Chem. Soc. 1988, 110, 5951 .

(8) Akhmedov, V.; Klabunde, K. J. J. Mol. Catal. 1988, 45, 193.

(9) Ichikawa, M.; Lang, A. J.; Shriver, D. F.; Sachtler, W. M. H. J. Am. Chem. Soc. 1985, 107,7216.

(10) (a) Garden, D.; Kemball, C.; Whan, D. A. J. Chem. Soc., Faraday

Trans. 1 1986, 82, 3113. (b) Faro, A. C.; Kemball, C. Ibid. 1986, 82, 3125.

(11) Davis, R. J.; Boudart, M. J. Phys. Chem. 1994, 98, 5471.

(12) Tzou, M. S.; Jiang, H. J.; Sachtler, W. M. H. Appl. Catal. 1986, 20,231 .
(13) Tzou, M. S.; Teo, B. K.; Sachtler, W. M. H. Langmuir 1986, 2 773

(14) (a) Moller, K.; Bein, T. J. Phys. Chem. 1990, 94, 845. (b) Moller, K.; Bein, T. In Zeolites: Facts, Figures, Future; Jacobs, P. A., van Santen, R. A., Eds.; Stud. Surf. Sci. Catal. 49; Elsevier: Amsterdam, 1989; pp 985994.

(15) Yermakov, Yu. I; Kuznetsov, B. N.; Zakharov, V. A. Catalysis by Supported Complexes; Elsevier: Amsterdam, 1981.

(16) Yermakov, Yu. I. Catal. Rev-Sci. Eng. 1976, 13, 77.

(17) Venter, J.; Kaminsky, M.; Geoffroy, G. L.; Vannice, M. A. J. Catal. $1987,103,450$.

(18) Fukuoka, A.; Kimura, T.; Ichikawa, M. J. Chem. Soc., Chem. Commun. 1988, 428.

(19) Braunstein, P.; Devenish, R.; Gallezot, P.; Heaton, B. T.; Humphreys, C. J.; Kervennal, J.; Mulley, S.; Ries, M. Angew. Chem., Int. Ed. Engl. 1988, 27, 927.

(20) Reviewed in: Sachtler, W. M. H. Zhang, Z Adv, Catal 1993, 39 , 129-220, Chapter VI.

(21) Rao, L.-F.; Fukuoka, A.; Ichikawa, M. J. Chem. Soc., Chem Commun. 1988, 458.

(22) Zhang, Z.; Suib, S. L.; Zhang, J. D.; Hines, W. A.; Budnick, J. I J. Am. Chem. Soc. 1988, 110, 5569.

(23) Breck, D. W. Zeolite Molecular Sieves; R. E. Krieger Publishing: Malabar, FL, 1984

(24) Zeolites: Facts, Figures, Future; Jacobs, P. A., van Santen, R. A. Eds.; Stud. Surf. Sci. Catal, 49; Elsevier: Amsterdam, 1989.

(25) Breck, D. W. Zeolite Molecular Sieves; R. E. Krieger Publishing: Malabar, FL, 1984

(26) Davis, M. E.; Lobo, R. F. Chem. Mater. 1992, 4, 756.

(27) Suib, S. L. Chem. Rev. 1993, 93, 803.

(28) Introduction to Zeolite Science and Practice; van Bekkum, H. Flanigen, E. M., Jansen, J. C., Eds.; Elsevier: Amsterdam, 1991.

(29) Borvornwattananont, A.; Moller, K.; Bein, T. J. Phys. Chem. 1992. 96,6713 .

(30) Borvornwattananont, A.; Bein, T. J. Phys. Chem. 1992, 96, 9447.

(31) (a) King, R. B.; King, A. D. J.; Tanaka, K. J. Mol. Catal. 1980 ,

10, 75. (b) Absi, H. M.; Brown, T. L. J. Am. Chem. Soc. 1977, 99, 2982 (c) Chipperfield, J. R.; Hayter, A. C.; Webster, D. E. J. Organomet. Chem. 1976, 121,185 .

(32) (a) Brown, T. L.; Ogino, K. Inorg. Chem. 1971, 10, 517. (b)

Schumann, H.; Feldt, W. Z. Allg. Anorg. Chem. 1979, 458, 257.

(33) Burlitch, J. M. J. Am. Chem. Soc. 1969, 91, 4562.

(34) Beveridge, A. D.; Clark, H. C. J. Organomet. Chem. 1968, 11, 601.

(35) Patmore, D. J.; Graham, W. A. G. Inorg. Chem. 1967, 6, 981.

(36) Carey, N. A. D.; Clark, H. C. Inorg. Chem. 1968, 7, 94.

(37) (a) Moller, K.; Borvornwattananont, A.; Bein, T. J. Phys. Chem. 1989, 93, 4562. (b) Borvornwattananont, A.; Moller, K.; Bein, T. J. Phys.

Chem. 1989, 93, 4205 .

(38) Bryan, R. F. J. Chem. Soc. A 1968, 696.

(39) Wells, A. F. Structural Inorganic Chemistry, 5th ed.; Clarendon Press: Oxford, 1984; p 1279. 